\title{
Platelet releasing activity in sera of patients with rheumatoid vasculitis
}

\author{
T J CUNNINGHAM, R L MEDCALF, J D MATHEWS, AND K D MUIRDEN
}

University of Melbourne, Department of Medicine, Rheumatology Unit, The Royal Melbourne Hospital, Victoria 3050, Australia

SUMMARY Platelet releasing activity was found in sera fractionated by $30 \%$ ammonium sulphate in seven of 11 patients with systemic rheumatoid vasculitis, two of 16 patients with cutaneous rheumatoid vasculitis, and three of 18 patients with clinically uncomplicated rheumatoid arthritis. Serial studies in three patients suggest a key role of platelet activation by serum factors in the pathogenesis of systemic rheumatoid vasculitis. IgG rheumatoid factor or IgG containing immune complexes, or both, may be responsible for this platelet releasing activity.

Key words: rheumatoid arthritis, platelets, platelet activation.

Platelet activation has been observed in many vascular disorders probably secondary to preexisting vessel damage. In the vascular damage such as occurs in rheumatoid vasculitis (RV) it is possible that platelet activation may also occur as the initiating or primary event. The liberation of permeability factors could then result in enhanced vascular permeability favouring the deposition of circulating immune complexes which may provoke subsequent inflammatory events. The classic experiments of Kniker and Cochrane ${ }^{1}$ showed the key role of increased vascular permeability in experimental immune complex mediated vascular damage. Platelets are the major intravascular source of the vasoactive amine serotonin and also contain a cationic protein which induces increased vascular permeability. $^{2}$ There is evidence of intravascular platelet release in rheumatoid disease. ${ }^{3}$ Furthermore, studies in vitro have shown the ability of IgG rheumatoid factor (IgG RF), IgG aggregates or complexes to activate platelets. ${ }^{4}$ Serum IgG RF levels correlate temporarily with the evolution of $\mathrm{RV}^{5}$. The present study therefore investigated the hypothesis that levels of such serum factors capable of activating platelets correlate with the manifestation and evolution of RV.

\section{Materials and methods}

PATIENTS AND CONTROL GROUPS

Patients were selected from the outpatient clinics or

Accepted for publication 4 June 1985.

Correspondence to Dr K D Muirden. wards of The Royal Melbourne, Prince Henry's, Alfred, Repatriation General, and St Vincent's hospitals, Melbourne. All had classical or definite rheumatoid arthritis (RA) by American Rheumatism Assocation criteria. They were divided into two groups - rheumatoid arthritis (RA) and rheumatoid vasculitis (RV) - on the criterion of past or present clinical manifestations of vasculitis (except nodules). The RV category was further subdivided into: $(a)$ mild RV (cutaneous vasculitis only) - MRV, (b) severe RV (visceral, neural, or extensive tissue involvement) - SRV, and (c) RV in remission (past documented vasculitis but none present at the time of examination) - RVR.

The control group consisted of healthy volunteers with no clinical evidence of disease.

\section{SERA}

$10-20 \mathrm{ml}$ of venous blood was drawn from each subject, placed in $10 \mathrm{ml}$ sterile plain tubes, and allowed to clot at $37^{\circ} \mathrm{C}$ for two hours. After centrifugation at $1500 \mathrm{~g}$ for 10 minutes serum was isolated, recentrifuged at $1500 \mathrm{~g}$ for 10 minutes to remove trace cellular elements, and then stored in $300 \mu \mathrm{l}$ aliquots at $-70^{\circ} \mathrm{C}$ until used.

B U F F E R S

Buffer $A$. Composition in mmol/l: $\mathrm{Na}^{+} 137 \cdot 4, \mathrm{~K}^{+}$ $5 \cdot 4, \mathrm{Mg}^{2+} 1 \cdot 2, \mathrm{SO}_{4}^{2-} 1 \cdot 2, \mathrm{HCO}_{3}^{-} 15 \cdot 0, \mathrm{H}_{2} \mathrm{PO}_{4}^{-} 1 \cdot 2$, $\mathrm{C1}^{-} 126 \cdot 6$, glucose $11 \cdot 5$.

Bovine serum albumin (BSA) was dialysed against this salt solution and then added to give a 
final concentration of $0.35 \%$. The $\mathrm{pH}$ was adjusted to approximately 6.0 with $1 \mathrm{M}$ citric acid.

Buffer B. Same as buffer $A$ with the addition of $2.5 \mathrm{mmol} / \mathrm{l} \mathrm{CaCl}$. The $\mathrm{pH}$ was adjusted to 7.4 by bubbling with $95 \% \mathrm{O}_{2}$ and $5 \% \mathrm{CO}_{2}$ (carbogen). Human fibrinogen (CSL) and dialysed BSA were added to give final concentrations of $0.05 \%$ and $0 \cdot 35 \%$ respectively.

Buffer C. Same as buffer B without fibrinogen.

FRACTIONATION OF SERA

$335 \mu$ l of saturated ammonium sulphate $\left[\left(\mathrm{NH}_{4}\right)_{2}\right.$ $\mathrm{SO}_{4}$ ] was added to $500 \mu \mathrm{l}$ of serum dropwise and with stirring to give a final concentration of $30 \%$ $\left(\mathrm{NH}_{4}\right)_{2} \mathrm{SO}_{4}$. The procedure was performed at $4^{\circ} \mathrm{C}$, and the solution was stirred for a further 20 minutes, then centrifuged at $10000 \mathrm{~g}$ for 20 minutes at $4^{\circ} \mathrm{C}$. The supernatant was aspirated and discarded and the protein precipitate redissolved in $500 \mu \mathrm{l}$ buffer C. This solution was then reprecipitated in $30 \%$ $\left(\mathrm{NH}_{4}\right)_{2} \mathrm{SO}_{4}$, centrifuged, and the supernatant discarded. The protein was finally resuspended in $250 \mu \mathrm{l}$ of buffer $\mathrm{C}$, effectively concentrating the fractionated sera by a factor of two. Each sample was then dialysed against BSA-free buffer $\mathrm{C}$ at $4^{\circ} \mathrm{C}$ for 24 hours to remove remaining $\left(\mathrm{NH}_{4}\right)_{2} \mathrm{SO}_{4}$. Dialysed serum fractions were then split into $60 \mu \mathrm{l}$ volumes and stored at $-70^{\circ} \mathrm{C}$ until use. Monomeric and heat aggregated IgG (see below (10 g/l)) were subjected to the same process and used as negative and positive controls respectively.

PREPARATION OF MONOMERICIGG AND HEAT A GGREGATED I gG

Human Cohn fraction II was dissolved in buffer $\mathrm{C}$ (initially without BSA) to a concentration of $60 \mathrm{~g} / \mathrm{l}$ and centrifuged at $37000 \mathrm{~g}$ for 20 minutes at $4^{\circ} \mathrm{C}$ to remove unwanted aggregates of IgG. The supernatant was removed and assayed for protein concentration (Lowry). ${ }^{6}$ Heat aggregated IgG (HAIgG) was prepared by heating approximately half of this in the stock solution of monomeric $\mathrm{IgG}$ at $63^{\circ} \mathrm{C}$ for 10 minutes, then cooling it on ice. Equal volumes of buffer $\mathrm{C}$ containing $0.4 \%$ BSA were added to both monomeric and HAIgG to give final stock solutions in $0.2 \%$ BSA. HAIgG and monomeric IgG were stored in aliquots at $-70^{\circ} \mathrm{C}$ and used within six weeks of preparation.

\section{PLATELET DONORS}

A panel of eight volunteers who had normal clinical examinations and full blood examinations were bled at approximately three to four weekly intervals. None had taken drugs known to affect platelet function in the preceding three weeks. Fractionated serum samples were tested on at least three different donors' platelets on at least three different occa- $\frac{\square}{\omega}$ sions.

PREPARATION OF WASHED HUMAN

PLATELETS

Suspensions of washed human platelets were prepared as described by Medcalf et al. ${ }^{7} 50 \mathrm{ml}$ of blood $\stackrel{\curvearrowright}{\varnothing}$

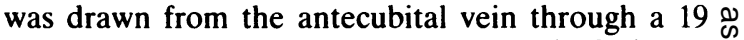
gauge needle into acid citrate dextrose (ACD) in a $\vec{\circ}$ polypropylene syringe. The final $\mathrm{ACD} / \mathrm{blood}$ ratio was $1 / 6$. After a sample had been taken for platelet $\vec{\omega}$ counting the mixture was transferred to polypropylene tubes and centrifuged at $125 \mathrm{~g}$ for $20 \stackrel{\varrho}{\mathrm{Q}}$ minutes at room temperature. The platelet rich $i$ plasma (PRP) was removed by a polypropylene ${ }_{-}^{\mathrm{T}}$ syringe and the $\mathrm{pH}$ adjusted to 6.0 with $1 \mathrm{M}$ citric $\vec{c}$ acid. PRP was then centrifuged at $1100 \mathrm{~g}$ at room temperature for 20 minutes, the supernatant discarded, and the platelet pellet resuspended in $7-10 \vec{c}$ $\mathrm{ml}$ of buffer $\mathrm{A}$. The resuspended platelets were recentrifuged at $1000 \mathrm{~g}$ for 7.5 minutes at room temperature, the supernatant aspirated, and the $₹$ platelet pellet resuspended and centrifuged as be- $\overrightarrow{0}$ fore. After aspiration of the supernatant the platelets were finally resuspended in buffer $B$ to a $\square$ concentration of $350000 / \mathrm{mm}^{3}\left(350 \times 10^{9} / \mathrm{l}\right)$. Apyrase (potato grade III, Sigma Chemical Company, Missouri) initially dissolved in saline to a concentration of $3.4 \mathrm{~g} / \mathrm{l}$ was added to the platelet suspension to $\frac{\circ}{\mathbb{D}}$ give a final concentration of $34 \mathrm{mg} / \mathrm{l}$. During the experiments the platelet suspension was kept in 10 을 $\mathrm{ml}$ polypropylene syringes (allowing no air exposure) at $37^{\circ} \mathrm{C}$.

$\left[{ }^{3}\right.$ H $]$ SEROTONIN RELEASE ASSAY

Platelet suspensions at concentrations of $350000 / \frac{2}{\sigma}$ $\mathrm{mm}^{3}\left(350 \times 10^{9} / 1\right)$ were incubated with $\left[{ }^{3} \mathrm{H}\right]$ serotonin (5-hydroxy $\left[\mathrm{G}-{ }^{3} \mathrm{H}\right]$ tryptamine creatine sulphate 8 aqueous solution containing $500 \mathrm{mCi} / \mathrm{mmol}$ (Amer- 3 sham, UK) for at least one hour, to give a finalo concentration of $5 \mu \mathrm{Ci} / \mathrm{ml}(5 \mathrm{mCi} / \mathrm{l}) .450 \mu \mathrm{l}$ of platelet suspension was initially reacted with $20 \mu \mathrm{l}$ of heparin (David Bull Laboratories) to give a final concentration of $20 \mathrm{U} / \mathrm{ml}$. The inclusion of heparinc was necessary as it had been previously shown in N initial studies that trace amounts of thrombin coprecipitated with the IgG fraction. Added heparin had negligible effect on the platelet activating ability of both monomeric IgG and HAIgG (data not shown). The platelet suspensions were then allowed to react with $50 \mu$ l of reagent (HAIgG, monomeric IgG, or fractionated serum) in small polypropylene ${ }_{0}^{-}$

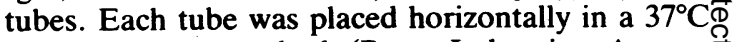
reciprocating water bath (Paton Industries, Australia) and shaken at 220 oscillations/minute for $10 \frac{\varrho}{\sigma}$ minutes. The reactions were stopped by the addition 
of $50 \mu$ l of paraformaldehyde (final concentration $1 \%)$. The complete volume of each reaction was layered on top of $1 \mathrm{ml}$ of percoll solution (adjusted to $1.0426 \mathrm{~g} / \mathrm{ml}(1042.6 \mathrm{~g} / \mathrm{l})$ at $20^{\circ} \mathrm{C}$ with buffer C) in plastic $\mathrm{P} 4$ tubes. The tubes were centrifuged at 1500 $g$ for 15 minutes at $4^{\circ} \mathrm{C}$ to remove platelets, aggregates, and debris. $200 \mu \mathrm{l}$ of the supernatant was added to $6 \mathrm{ml}$ of scintillant, mixed, and counted in a beta counter (Packard liquid scintillation spectrometer model 3380). $200 \mu \mathrm{l}$ of unactivated and uncentrifuged platelets diluted with equivalent volumes of reagents to match test solutions was similarly treated to determine the total radioactivity present in the platelet preparation. The percentage serotonin release was calculated as:

(activity $(\mathrm{cpm})$ in test sample - background activity) $\times 100$

$$
\text { total activity - background activity }
$$

Platelet releasing activity (PRA) was considered to be significant if test samples induced a release of greater than $13 \%$ of $\left[{ }^{3} \mathrm{H}\right]$ serotonin on the basis of studies on control sera and the lack of associated platelet aggregation below this level. In a study by Medcalf et al. ${ }^{9}$ the release of approximately $13 \%$ of endogenous serotonin from washed human platelets was necessary to contract a human smooth muscle preparation in vitro. This level of serotonin release could be achieved by $20 \mathrm{mg} / \mathrm{l}$ of heat aggregated IgG.

IMMUNE COMPLEXES AND IgG RF

The Clq binding assay and IgG RF were assayed as previously described. ${ }^{8} 9$

\section{Results}

Variations in sensitivity of platelet preparations to aggregating agents were noted between donors and in the same donor bled on different occasions. In general, female donors showed greater sensitivity than male, in agreement with the findings of Moore et al. ${ }^{10}$ Fractionated test sera and control solutions were therefore allowed to react with the same panel of donors, and the mean release of $\left[{ }^{3} \mathrm{H}\right]$ serotonin from at least three reactions was calculated (Fig. 1). To determine whether the fractionation process itself was creating non-specific platelet releasing activity (i.e. IgG clumping), $1 \mathrm{~g} / 1$ monomeric IgG and various control sera were similarly fractionated but failed to cause significant platelet serotonin release.

In seven of 11 fractionated sera from patients with active severe RV (SRV) and in two of 16 patients with cutaneous rheumatoid vasculitis (MRV) significant platelet releasing activity (PRA) was shown $(p<0.05$, Mann-Whitney $U$ test). All of six patients with past severe RV currently in remission (RVR) and nine of 10 control subjects $(C)$ showed negligible serotonin releasing activity. Three of 18 patients with RA lacking clinical signs of RV had significant PRA in their fractionated sera (Fig. 2). In three cases of RV tested serially fractionated serum from the active disease phase caused significant serotonin release, in contrast with the effect of fractionated serum taken after treatment and clinical remission (Fig. 3). In the RA and RV categories PRA did not correlate significantly with platelet count, IgG RF (Fig. 4), Rose-Waaler titre, erythrocyte sedimentation rate, or immune complex levels by the $\mathrm{Clq}$ binding assay $(\mathrm{r}$ values $=-0.09,0 \cdot 18,0.01,-0 \cdot 18$, $\mathbf{0 . 0 9}$ respectively).

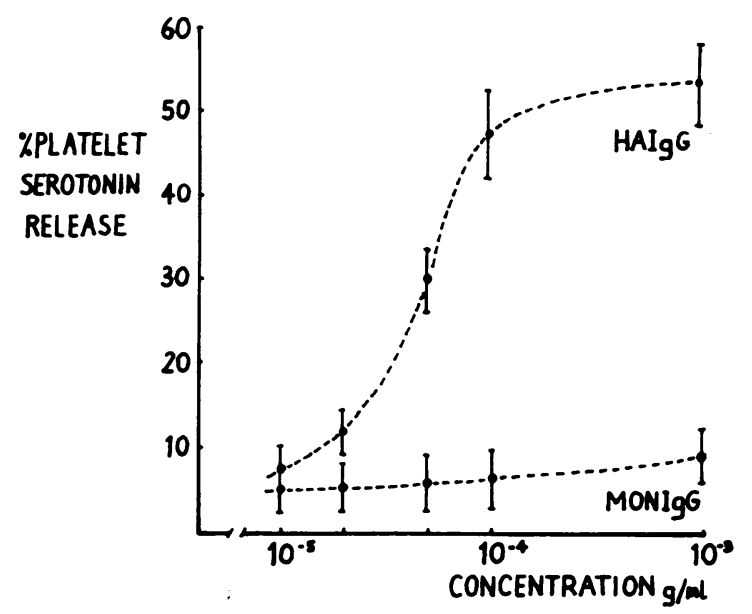

Fig. 1 Heat aggregated IgG concentration dependent platelet serotonin release.

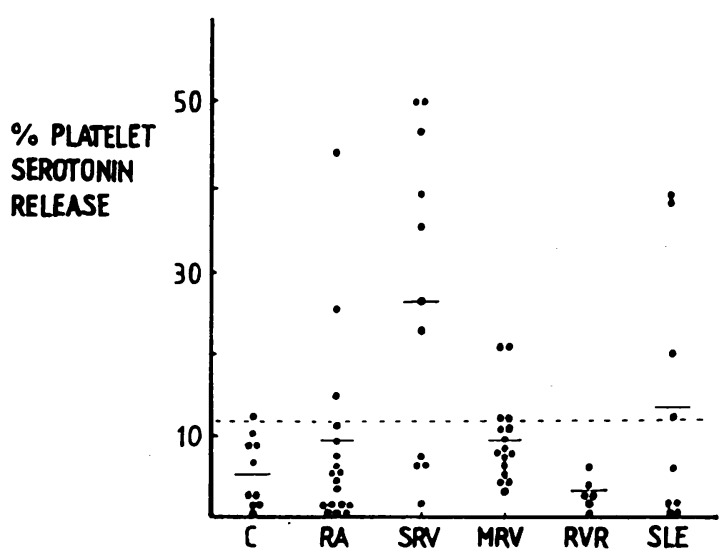

Fig. 2 Percentage platelet serotonin release $\mathrm{v}$ diagnosis. 

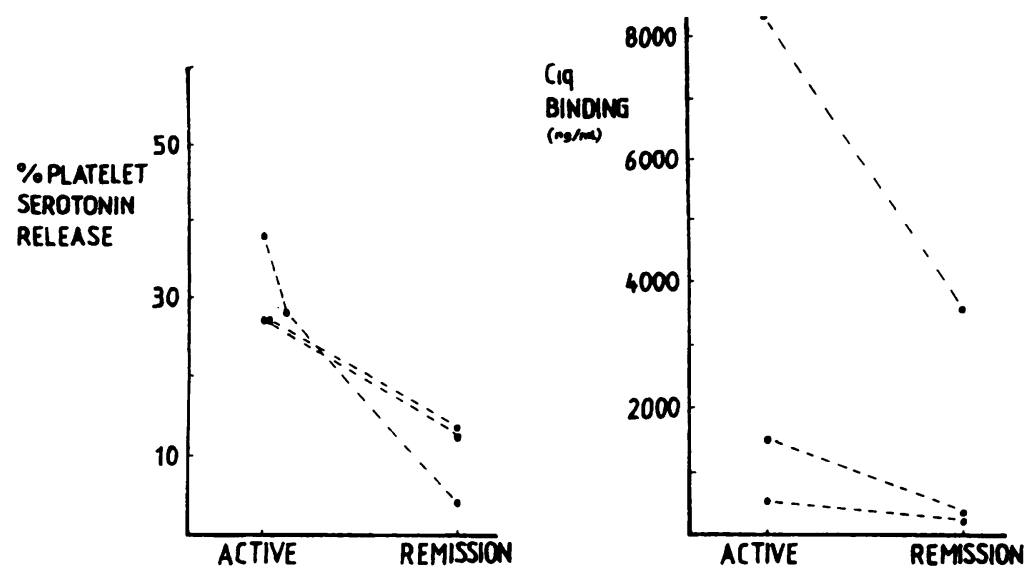

Fig. 3 Serial studies of releasing activity and Clq binding in SRV. $(n g / m l=\mu g / l)$.

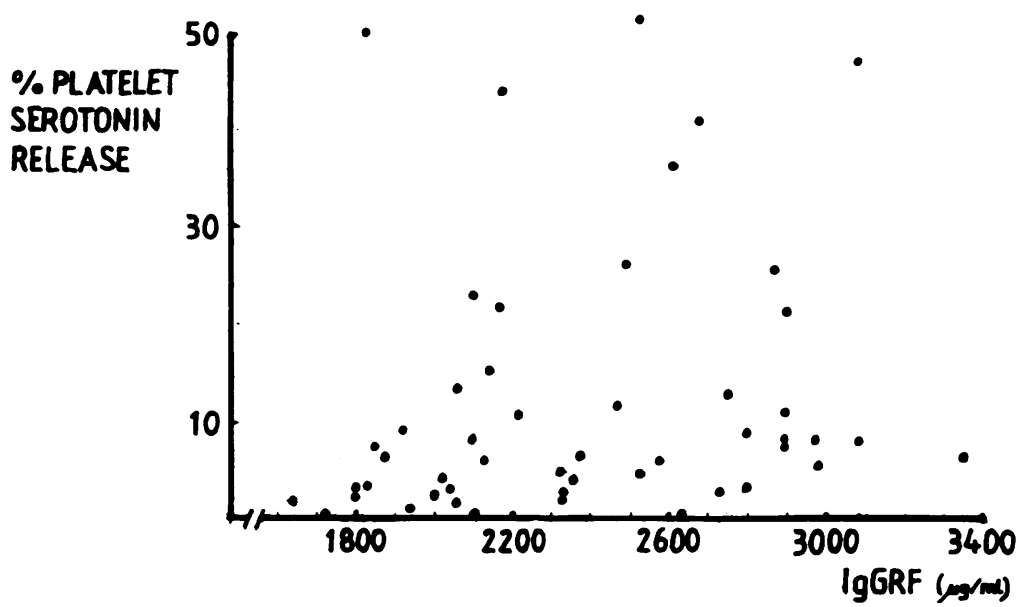

Fig. 4 Percentage platelet serotonin release $v \operatorname{IgG} R F(r=0 \cdot 18 \mathrm{NS})$. $(\mu g / m l=m g / l)$.

\section{Discussion}

This study indicates that fractionated sera of some RA and some RV patients have the ability to cause the release of significant concentrations of serotonin from normal platelets and permits speculation of similar events in vivo. The fractionation of serum with $30 \%$ ammonium sulphate does not remove IgM RF, which Wager et al. ${ }^{11}$ found to be an inhibitor of immune complex induced platelet aggregation in vitro. IgM RF was still present in fractionated serum as shown by the persistence of positive latex and Rose-Waaler agglutination tests. Thus it could be suggested that the inhibitory effect of IgM RF may be overcome in vivo if sufficient concentrations of platelet releasing substance(s) are present. Although some fractionated sera induced platelet activation, this was not seen in the corresponding unfractionated serum samples, indicating the improbability of antiplatelet antibodies having any 0 significant role in RV. The fractionation process is ? mainly operative in reducing the concentration of $\frac{D}{0}$ monomeric IgG, the major inhibitory component of normal human serum to platelet activation by $N$ immune complexes. ${ }^{12}$ The work of Clark et al. ${ }^{13}$ indicated that platelet activation by immune complexes may still occur in the presence of plasma. Platelet aggregation and release occurred exclusively during the formation of precipitating immune complexes at antigen-antibody equivalence. The $\stackrel{\Phi}{\sim}$ inhibition offered by $\mathrm{C} 1 \mathrm{q}$ to platelet activation by IgG containing complexes, ${ }^{14}$ if significant at all, may be reduced during complement consumption, which $\mathbb{\nabla}$ also occurs in RV.

It is suggested that platelet release by serum factors is a localised event in view of the local 
clinical manifestations of vasculitis and the lack of hypertension which would result from the vasoconstrictive effect of generalised platelet serotonin release. The inhibition of platelet release may alter with changes in microcirculatory blood flow and the varying molecular environment of platelets.

This study found no correlation between PRA of fractionated RA or RV sera and platelet count. Platelet release without aggregation may occur, ${ }^{15}$ and platelets that have undegone the release reaction may circulate with a near normal life span. ${ }^{16}$ It thus appears that activation and release need not necessarily be coupled to sequestration of platelets. Furthermore, a mild degree of platelet loss may be compensated for by increased production. An increase in platelet turnover has been recorded in rheumatoid disease. ${ }^{17}$

The temporal relationship of PRA to active clinical vasculitis in three patients tested serially and the lack of PRA in RV in remission suggest a possible pathogenic role. The presence of PRA in a few patients without clinical vasculitis may relate to a higher prevalence of subclinical vasculitis as shown by the histological studies of Kulka, ${ }^{18}$ who found an incidence of vasculitis in skeletal muscle tissue in $20 \%$ of RA autopsies. It also appears that the subsequent pathogenic processes leading to clinical vasculitis (probably starting with complement activation) need not necessarily follow platelet release and immune complex deposition. Skin biopsy studies have in fact shown a relatively high incidence of positive immunofluorescence in histologically and clinically normal skin. ${ }^{19}$

The nature of PRA in RV sera remains unknown. However, it seems likely that it is due to IgG RF- or IgG-containing immune complexes. The lack of correlation between IgG RF, C1q, and PRA does not negate this. The IgG RF assay used in this study, like most other techniques, probably does not give a true indication of levels of aggregated or complexed IgG RF. The C1q assay was performed on serum, whereas the PRA was performed on serum fractions. It is also possible that the PRA is related to non-complement binding immune complexes. Valone et al. ${ }^{15}$ identified the PRA in synovial fluid as IgG complexes. In RA the majority of material measured as immune complexes is composed of IgG and rheumatoid factors of several immunoglobulin classes. ${ }^{20}$ Furthermore, clinical correlative studies such as those by Scott et al. ${ }^{5}$ Theofilopoulos, ${ }^{21}$ and Allen et al. $^{22}$ show that high levels of IgG RF are strongly associated with clinical RV, serum anticomplementary activity, and depressed C4 levels. As immune complexes containing only IgG RF are reported to be incapable of activating complement ${ }^{23}$ it may be that their putative action on platelets enables the deposition of other complement fixing complexes. Alternatively, mixed IgG RF and IgM RF complexes, which activate complement, may also cause platelet release. Such complexes have been isolated from RA sera, ${ }^{24}$ but their ability to activate platelets has not been tested.

The PRA detected in a proportion of systemic lupus erythematosus (SLE) sera is probably due to antiplatelet antibodies. ${ }^{25} \mathrm{~A}$ recent study suggests that specific antiplatelet antibodies exist in RA $24 \%$ of decomplemented RA sera causing significant platelet serotonin release. ${ }^{26}$ The present study found no significant serotonin release by unfractionated RA sera: the disparity does not appear totally explicable by methodological differences between the studies. Norberg ${ }^{27}$ found indirect evidence of platelet antibodies in only two of 36 RA sera. Further work is required to characterise PRA in RA.

Comparative platelet sensitivity to activating agents between RA patients (treated and untreated) and controls remains unknown except for one study reporting that most RA patients had an enhanced platelet sensitivity to collagen and epinephrine. ${ }^{28}$ Obviously, comparative sensitivity to IgG aggregates/immune complexes would be relevant.

This study indicates that there may be a role for antiplatelet agents in vasculitis prone patients. Aspirin in high dosage, as is often administered to RA patients, may detrimentally alter the balance of prostacyclin/thromboxane A2 production to favour platelet aggregation. Sulphinpyrazone may be beneficial in inhibiting primary or secondary involvement of platelets in the vasculitic process. Agents reducing the permeability of the endothelial barrier such as hydroxyethylrutosides ${ }^{29}$ may modify the initial events leading to vasculitis.

The authors wish to thank Ms A Robinson and Ms A Cox for their work on the C1q binding and IgG RF assays and Ms J Vagg for her typing expertise. TJC was supported by an NH and MRC Research Scholarship.

\section{References}

1 Kniker W T, Cochrane C G. Localisation of circulating antigen-antibody complexes in serum sickness: the role of vasoactive amines and hydrodynamic forces. J Exp Med 1968; 127: $119-35$

2 Madman R L. Wekster B, Ferris B. Increased vascular permeability provided by human platelet cationic extract. J Clin Invest 1970; 49: 274-81.

3 Zeller J, Weissbarn E, Banith B, Mieke H, Deicher $\mathrm{H}$, Serotonin content of platelets in inflammatory rheumatic disease. Arthritis Rheum 1983; 26: 532-40.

4 Fink $\mathrm{P}$ C, Piercing U, Fricke $M$, Diecher $H$. Platelet aggregation and aggregation inhibition by different antiglobulins and antiglobulin complexes from sera of patients with rheumatoid arthritis. Arthritis Rheum 1979; 22: 896-903. 
5 Scott D G I, Bacon P A, Allen C. Elson C J, Wallington T. IgG rheumatoid factor, complement and immune complexes in rheumatoid synovitis and vasculitis: comparative and serial studies during therapy. Clin Exp Immunol 1981; 43: 54-63.

6 Lowry O H, Rosenbrough M J, Faarr A L. Randall R J. Protein measurement with folin phenol reagent. J Biol Chem 1951; 193: 265-75.

7 Medcalf R L, Iwanov V. Moulds R F. Responses of human arterial muscle to stable vasoactive substances released from human platelets by collagen and heat aggregated IgG. Clin Exp Pharmacol Physiol 1983; 10: 567-8.

8 Zubler R H, Nydegger U, Perrin L H, et al. Circulating and intra-articular immune complexes in patients with rheumatoid arthritis. J Clin Invest 1976; 57: 1308-18.

9 Hay F C, Nineham L J, Roitt I M. Routine assay for detection of IgG and IgM antiglobulins in seronegative and seropositive rheumatoid arthritis. Br Med J 1975; iii: 203-4.

10 Moore A, Weksler B. Nachman R L. Platelet Fc (IgG) receptor: increased expression in female platelets. Thromb Res 1981: 21: 469-74.

11 Wager O. Penttinen K. Rasanen A. Myllyla G. Inhibition of IgG complex-induced platelet aggregation by antiglobulin active cryoglobulin IgM components. Clin Exp Immunol 1973: 15: 393-408.

12 Kekomaki R. Myllyla G. Effect of normal human serum on the binding of specific antibodies and platelet-unrelated immune complexes to human platelets. Scand J Immunol 1979: 9: 527-35.

13 Clark W F, Tevaarwerk J J M, Bandall K, Lindsay R M, Linton A $\mathrm{L}$. Platelet aggregation and release associated with immune complex formation in pig plasma. J Lab Clin Med 1980; 96: 654-65.

14 Pfueller S L, Luscher E F. The effects of aggregated immunoglobulins on human blood platelets in relation to their complement fixing abilities. J Immunol 1972; 109: 517-25.

15 Valone T H, Austen K F, Goetal E J. Identification of the platelet activating activity in rheumatoid synovial fluid as an intermediate molecular weight complex of IgG. J Immunol 1979: 122: 703-9.

16 Reimers H J, Kinlough Rathbone R L. Cazanave J P, et al. In vitro and in vivo functions of thrombin treated platelets. Thromb Haemost 1976; 35: 151-66.
17 Hutchinson R M. Davis P. Jayson M I V. Thrombocytosis in rheumatoid arthritis. Ann Rheum Dis 1976; 35: 138-42.

18 Kulka J P. The vascular lesion associated with rheumatoid arthritis. Bull Rheum Dis 1959: 10: 201-5.

19 Conn D L, Schroeter A L. McDuffie F C. Cutaneous vessel immune deposits in rheumatoid arthritis. Arthritis Rheum 1976: 19: $15-20$

20 Fink P C. Schedel I. Deicher H. Estimation of IgG antiglobulins in sera of patients with rheumatoid arthritis and chronic liver disorders. Klin Wochenschr 1976: 54: 601.

21 Theofilopoulos A N, Bursonboy G, Lo Spalluto J J. Ziff M IgG rheumatoid factor and low molecular weight IgM - an assocation with vasculitis. Arthritis Rheum 1974; 17: 272-84.

22 Allen C. Elson C J. Scott D G I. Bacon P A. Bucknall R C. IgC antiglobulins in rheumatoid arthritis and other arthritides. Relationship with clinical features. Ann Rheum Dis 1981: 40: 127-32.

23 Pope R M. Teller D C. Mannik M. The molecular basis of self co association of IgG rheumatoid factors. J Immunol 1975: 115: 365-73.

24 Elson C J. Scott D G I. Blake D R. Bacon P A. Holt P J. Complement activating rhcumatoid factor containing complexes in patients with rheumatoid vasculitis. Ann Rheum Dis 1983:42: 147-50.

25 Hirschman R J. Schulman N R. The use of platelet serotonin release as a sensitive method for detecting anti-platelet antibodies and a plasma anti-platelet factor in patients with idiopathic thrombocytopenia purpura. Br J Haematol 1973: 24: 793-802.

26 Weibarth E. Banith B. Mielke H. Luman W. Deicher H. O Platelets as target cells in rheumatoid arthritis and systemic lupus arthritis. A platelet specific immunoglobulin inducing the release reaction. Rheumatol Int 1982: 2: 67-73.

27 Norberg R. IgG complexes in serum of rheumatoid arthritis patients. Scand J Rheumatol 1974: 3: 229-36.

28 Colli S. Maderna P. Tremoli E. Colombo F. Canesi B. Platelet function in rheumatoid arthritis. Scand J Rheumatol 1982: 11: $139-43$.

29 Svensjo E. Arfors K. Arturson G. Bergquist D. Rutili G. Effects of $O$-(B-hydroxyethyl)rutoside (HR) on macromolecular permeability in the hamster cheek pouch microvasculature. In: Kapperk A. ed. New trends in venous diseases. Bern. Stuttgart. Vienna: Hans Huber. 1977: 296-307. 